\title{
lloprost improves running performance at 5,000 m in Han but not in Tibetans
}

\author{
Bengt Kayser ${ }^{1, *}$, Jui-Lin Fan', Liya Nan², Wang Liang Bang², Bianba ${ }^{3} \&$ Tianyi Wu² \\ 1 Institute of Sport Sciences, University of Lausanne, Lausanne, Switzerland \\ 2 National Key Laboratory of High Altitude Medicine, Department of Hypoxic Physiology and Mountain Medicine, High Altitude Medical Research \\ Institute, Xining, Qinghai, P. R. China. \\ 3 Tibet University Medical College, Lhasa, Tibet, P. R. China \\ * Corresponding author: Prof. Dr. Bengt Kayser, Institute of Sport Sciences, University of Lausanne, \\ Synathlon Uni-Centre, 1015 Lausanne, Switzerland \\ E-Mail: bengt.kayser@unil.ch
}

\section{ORIGINAL ARTICLE}

\section{Article History:}

Submitted $11^{\text {th }}$ July 2018

Accepted $20^{\text {th }}$ December 2018

Published $12^{\text {th }}$ March 2019

Handling Editor:

Arno Schmidt-Trucksäss

University of Basel, Switzerland

Editor-in-Chief:

Martin Kopp

University of Innsbruck, Austria

Reviewers:

Reviewer 1: Anonymous

Reviewer 2: Anonymous

\section{ABSTRACT}

Background: Tibetans lose less aerobic exercise capacity in hypoxia compared to lowland Han. We tested if inhalation of iloprost (to counter hypoxic pulmonary vasoconstriction) and furosemide (to decrease afferent vagal traffic from pulmonary receptors) improve performance in hypoxia in Han compared to Tibetans. Methods: 8 Tibetans and 8 Han, living at 2,260 m, did incremental uphill treadmill running to exhaustion at ambient pressure on day 1, followed by three runs at $5,000 \mathrm{~m}$ (hypobaric chamber) after inhalation of iloprost (ILO), furosemide (FUR) or placebo (PLA), on different days in a counter-balanced order. Results: In Han the performance decrement from 2,260 m to 5,000 $m$ was greater than in Tibetans ( $p<0.05)$. In Han iloprost improved performance at 5,000 m compared to placebo ( $p<0.05$ vs. PLA); furosemide had no effects. In Tibetans there were no treatment effects. Peripheral $\mathrm{O}_{2}$ saturations at peak exercise at $5,000 \mathrm{~m}$, were higher by $\sim 8 \%$ in the Tibetans $(\mathrm{p}<0.05$ vs. Han). Maximum heart rate was lowered by $13 \pm 6 \mathrm{bpm}$ in Han at 5,000 m regardless of treatment compared to $2,260 \mathrm{~m}(\mathrm{p}<0.05)$. Tibetans reached similar maximum heart rates $\sim 200 \mathrm{bpm}$ at 5,000 $\mathrm{m}$ and 2,260 $\mathrm{m}$, independent of treatment. Conclusions: The blunting of the exercise impairment in severe hypoxia in Han during maximal exercise after inhalation of iloprost suggests that hypoxic pulmonary vasoconstriction and right ventricular function are potential performance limiting factors in Han in hypoxia.

Keywords:

altitude - cardiac - pulmonary - right ventricle - heart rate - performance

Citation:

Kayser, B., Fan, J.-L., Nan, L., Bang, W. L., Bianba \& Wu, T. (2019): lloprost improves running performance at 5,000 m in Han but not in Tibetans. Current Issues in Sport Science, 4:002. doi: 10.15203/CISS_2019.002

\section{Introduction}

Exercise-induced arterial hypoxemia impairs maximum aerobic capacity (Dempsey \& Wagner, 1999; Nielsen, 2003). This effect is exacerbated at high altitude because of lower inspiratory oxygen tension $\left(\mathrm{PiO}_{2}\right.$ ) (Amann \& Calbet, 2008). Up to altitudes $\sim 4,000 \mathrm{~m}$ the loss of aerobic capacity in hypoxia is determined by a decrease in arterial oxygen saturation $\left(\mathrm{SaO}_{2}\right)$ and thus arterial oxygen concentration $\left(\mathrm{CaO}_{2}\right)$ and mass arterial oxygen flux $\left(\mathrm{CaO}_{2} \times\right.$ cardiac output $\left.=\mathrm{QaO}_{2}\right)$ (Amann \& Calbet, 2008; Chapman, Emery, \& Stager, 1999; Chapman, Stager, Tanner, Stray-Gundersen, \& Levine, 2011; Ferretti, Moia,
Thomet, \& Kayser, 1997). However, during exercise in more severe hypoxia (above $\sim, 000 \mathrm{~m}$ ), when $\mathrm{SaO}_{2}$ drops below 80 $\%$ (Wagner, 2000), there are unexplained reductions in both maximum heart rate and cardiac output (Amann \& Kayser, 2009; Boushel et al., 2001; Kayser, Narici, Binzoni, Grassi, \& Cerretelli, 1994; Mourot, 2018). The impaired maximal cardiac function at peak exercise in hypoxia is restored rapidly by increasing $\mathrm{PiO}_{2}$ to normoxic levels, enabling heart rate and cardiac output to further increase with increasing exercise intensity. The underlying mechanisms of the impaired maximum heart rate and associated reduction in cardiac output in severe hypoxia remain uncertain. 
A possible explanation for the drop in cardiac output in hypoxia is the development of hypoxic pulmonary vasoconstriction (HPV) (Naeije \& Chesler, 2012; Naeije et al., 2010) . Whilst controversy remains, HPV-induced pulmonary hypertension would lead to right ventricular over-load, limiting cardiac output and impairing maximum aerobic capacity (Anholm \& Foster, 2011; Naeije, 2011). Among Han lowlanders acutely exposed to an altitude of 3,700 m, $61 \%$ developed borderline or confirmed HPV and had impaired right ventricular function at high altitude. This compromised their cardiorespiratory fitness in relation to their mean pulmonary arterial pressure (PAP) (Yang et al., 2014). Tibetans, a well-adapted high altitude population (Wu \& Kayser, 2006), have a blunted HPV (Groves et al., 1993), maintain higher arterial oxygen saturation (Marconi et al., 2004; Wu \& Kayser, 2006), reach higher peak heart rates and show less performance decrement during hypoxic exercise compared to Han lowlanders (Marconi et al., 2004; Niu, Wu, Li, Chen, \& Song, 1995; Sun et al., 1990; Wu \& Kayser, 2006; Zhou, Zhuang, Wu, Zhang, \& Cherdrungsi, 2008; Zhuang et al., 1993). If the greater loss of aerobic performance in hypoxia of Han compared to Tibetans is due to more HPV, the inhalation of iloprost, a prostacyclin analogue which decreases pulmonary vascular resistance (Olschewski et al., 2002; Waxman \& Zamanian, 2013) and improves endurance exercise performance in primary pulmonary hypertension patients (Wensel, Opitz, Ewert, Bruch, \& Kleber, 2000) could potentially improve endurance exercise performance in hypoxia in Han as compared to Tibetans.

Another possible explanation for the observed decrease in lower peak heart and cardiac output in lowlanders exercising in severe hypoxia is increased parasympathetic activity (Boushel et al., 2001). A potential origin for increased parasympathetic activity is activation of pulmonary vagal afferents caused by subclinical interstitial pulmonary oedema from hypoxia and exercise-induced increased PAP (Anholm, Milne, Stark, Bourne, \& Friedman, 1999; Bhagat et al., 2011; Cremona et al., 2002; Lee \& Pisarri, 2001; Paton, 1998). Inhaled furosemide alleviates dyspnoea and improves endurance exercise performance under certain pathological conditions, possibly through pulmonary vagal afferent inhibition (Jensen, Amjadi, HarrisMcAllister, Webb, \& O'Donnell, 2008; Newton, Davidson, Macdonald, Ollerton, \& Krum, 2008; Parshall et al., 2012). We hypothesized that inhalation of furosemide by preventing activation of pulmonary vagal receptors would increase peak heart rate and improve endurance exercise performance in hypoxia in Han but not in Tibetans.

We therefore assessed endurance exercise performance in Tibetans and Han living at 2,260 m during incremental uphill treadmill running, first at ambient pressure and then in a hypobaric chamber at a simulated altitude of 5,000 m. We compared the effect of inhaled iloprost, furosemide and placebo on running performance at 5,000 m expecting that iloprost and furosemide would improve performance during incremental treadmill running in severe hypoxia in Han but not in Tibetans.

\section{Methods}

\section{Participants}

Two groups of eight healthy non-smoking Han and Tibetan men volunteered to participate (Table 1). The Han were born and raised in Xining $(2,260 \mathrm{~m})$ and had lived there for most of their lives. The Tibetans (and their parents) were born at altitude $(3,778 \pm 196 \mathrm{~m}$, mean $\pm \mathrm{SD})$ and were studying in Xining $(2,260$ $\mathrm{m}$ ) since 1-3 yr, spending their summer and winter holidays at home $(3,750$ to $4,280 \mathrm{~m})$. They were recruited by word of mouth from the local student population.

All participants were seen by a physician for a medical history and a physical examination. Inclusion criteria were age 18-25 years, parents and grandparents of exclusively Tibetan or Han ethnicity, respectively, and no contra-indications for exercise stress testing. The protocol was approved by the Qinghai High

Table 1: Participant characteristics.

\begin{tabular}{lcc}
\hline & Tibetan & Han \\
\hline $\mathrm{N}$ & 8 & 8 \\
Age $(\mathrm{yr})$ & $20 \pm 2$ & $20 \pm 1$ \\
$\mathrm{Height}(\mathrm{cm})$ & $171 \pm 5$ & $179 \pm 4^{*}$ \\
Body mass (kg) & $59 \pm 8$ & $77 \pm 18^{*}$ \\
Time spent at altitude (yr) & $19 \pm 2$ & $19 \pm 1$ \\
$\mathrm{ABP}(\mathrm{sys} / \mathrm{dia}, \mathrm{mmHg})$ & $116 \pm 10 / 72 \pm 6$ & $128 \pm 11 / 77 \pm 10$ \\
$\mathrm{SaO}(\%)$ & $94 \pm 1$ & $94 \pm 2$ \\
$\mathrm{Hb}(\mathrm{g} / \mathrm{L})$ & $158 \pm 9$ & $164 \pm 9^{1}$ \\
$\mathrm{Ht}(\%)$ & $47 \pm 2$ & $49 \pm 2$ \\
\hline
\end{tabular}

${ }^{*} p<0.05 ;{ }^{1} p=0.09 ; \mathrm{ABP}$ : arterial blood pressure; $\mathrm{SaO}_{2}$ : pulse oximetry; $\mathrm{Hb}$ : haemoglobin; $\mathrm{Ht}$ : haematocrit 
Altitude Medical Science Institutional Committee on Human Research. Written informed consent was obtained from all participants, in accordance with the Declaration of Helsinki.

\section{Resting measurements}

At ambient pressure, after 5-10 min rest sitting, blood pressure was measured by auscultation using a sphygmomanometer, and heart rate and saturation $\left(\mathrm{SaO}_{2}\right)$ with a finger oximeter (Nonin, Plymouth, MN, USA) in triplicate with 2 min intervals and averaged. A supine resting ECG was then recorded. A venous blood sample was taken from a cubital vein for the determination of haemoglobin concentration ([Hb]) and haematocrit (Hct) (Sysmex 2000i, Siemens, Munich, Germany).

\section{Exercise test}

The participants performed incremental exercise tests on a treadmill ( $\mathrm{h} / \mathrm{p} /$ Cosmos, Rome, Italy), first walking and then running, according to a modified Bruce protocol (3 min stages at the following speeds and slopes: $2.7 \mathrm{~km} / \mathrm{h}$ at $0 \%$ (warmup), $2.7 \mathrm{~km} / \mathrm{h}$ at $10 \%$ (stage 1), $4.0 \mathrm{~km} / \mathrm{h}$ at $12 \%$ (stage 2), 5.4 $\mathrm{km} / \mathrm{h}$ at $14 \%$ (stage 3), $6.8 \mathrm{~km} / \mathrm{h}$ at $16 \%$ (stage 4 ), $8.0 \mathrm{~km} / \mathrm{h}$ at $18 \%$ (stage 5), until voluntary exhaustion under strong verbal encouragement. We chose running over cycling in order to allow the participants to engage in a type of large muscle group effort they were well-accustomed to. Ear pulse oximetry and 12 lead pre-cordial ECG were continuously monitored (Masterscreen, Carefusion, Höchberg, Germany).

\section{Simulated altitude measurements}

The exercise testing at a simulated altitude of 5,000 m was done in a hypobaric chamber with no blinding to the condition (High Altitude Medical Research Institute, Xining, Qinghai, China). The pressure was gradually lowered over $40 \mathrm{~min}$ to reach the final altitude. Fractions of oxygen and carbon-dioxide were monitored by the chamber's control system and kept at their normal ambient values. Total exposure time lasted 3 to $4 \mathrm{hr}$ per session. The intervention consisted of iloprost (5 $\mu \mathrm{g}$ in saline, Roche, Switzerland), furosemide (40 $\mathrm{mg}$ in saline, Mepha, Basel, Switzerland) or placebo (saline only), inhaled over 10-15 $\mathrm{min}$ with an ultrasound nebulizer (AeronebGO, Galway, Ireland) each on a different day. After decompression the participants inhaled the intervention substance, according to a between-group counter-balanced randomization scheme to prevent bias from repeated simulated altitude exposure. The sequence list for the participants was identical in the two groups: 1-3-2, 2-1-3, 3-2-1, 1-3-2, 2-1-3, $3-2-1,1-3-2,2-1-3$, where 1 was placebo, 2 furosemide and 3 iloprost. Participants and experimenters were blinded to the substances. The participants then mounted the treadmill. After a standing resting measurement they started exercising until they reached voluntary exhaustion under strong verbal encouragement. At the completion of the exercise test the participant was gradually decompressed to the ambient atmospheric pressure over $30 \mathrm{~min}$.

\section{Analysis and statistics}

Resting measurements at ambient pressure and at 5,000 m in the chamber were compared with t-tests. We analysed the effects of ethnicity and treatment (i.e. placebo, furosemide or iloprost) during exercise using a two-way (ethnicity and treatment) ANOVA. Pairwise comparisons (Tukey HSD) were then performed between means. Data are presented as mean \pm SD or $95 \%$ confidence interval $(\mathrm{Cl})$. An a-level of 0.05 was used to interpret our findings. Analysis was done with SPSS (22, IBM, NY, USA) and Prism (6.0f, Graphpad, La Jolla, CA, USA).

\section{Results}

Resting variables at ambient pressure $(2,260 \mathrm{~m})$

Participant characteristics and resting values are shown in Table 1. Han and Tibetans were similar with the exception of the slightly higher stature and body mass of the Han.

\section{Simulated altitude of $5,000 \mathrm{~m}$}

Exposure to 5,000 $\mathrm{m}$ was well tolerated; none of the participants reported signs of acute mountain sickness. There were no side effects reported of the inhalation of placebo, iloprost or furosemide. Resting ECG was normal in all conditions, with sinus tachycardia during exposure to 5,000 m. Two out of eight Han and two out of eight Tibetans had slight right axis deviations. On average acute exposure to 5,000 $\mathrm{m}$ lowered total (placebo) exercise time by $127 \pm 64 \mathrm{sec}(\mathrm{P}<0.001$ vs. $2,260 \mathrm{~m})$.
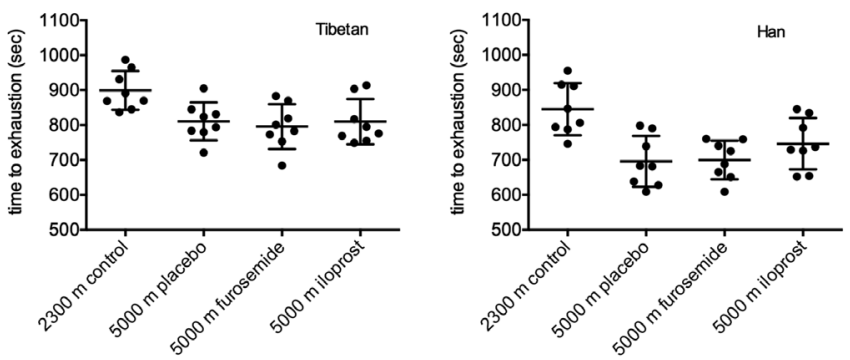

Figure 1: Time to exhaustion during incremental uphill running. Dots indicate individuals. Bars and flankers indicate means $\pm S D$.

Regardless of the altitude, exercise time was consistently better in Tibetans ( $\mathrm{P}=0.020$ vs. Han). Compared to $2,260 \mathrm{~m}$, exercise time at $5,000 \mathrm{~m}$ was shortened by $10 \%$ for Tibetans $(\mathrm{P}<0.001)$ and by $18 \%$ for $\operatorname{Han}(\mathrm{P}<0.001)$, the Tibetans exercising significantly longer than the $\operatorname{Han}(P=0.006)$. Compared to placebo, furosemide inhalation did not change exercise time in Tibetans $(P=0.399)$ or Han $(P=0.823)$. Meanwhile, iloprost 
inhalation improved exercise time in $\operatorname{Han}(P=0.008)$ but not in Tibetans $(P=0.419)$. As a result, no significant difference in exercise time was observed anymore between the Han and Tibetan upon iloprost inhalation.

\section{Saturation}

Ascent to 5,000 $\mathrm{m}$ lowered $\mathrm{SaO}_{2}$ in both Tibetans and Han $(\mathrm{P}<0.001)$, an effect exacerbated with exercise $(\mathrm{P}=0.001)$. A smaller reduction in $\mathrm{SaO}_{2}$ was observed in the Tibetans during exercise compared to Han (interaction: $\mathrm{P}=0.040$ ). As a result $\mathrm{SaO}_{2}$ during exercise was consistently higher in Tibetans compared to Han ( $\mathrm{P}=0.008)$. Accordingly, $\mathrm{CaO}_{2}$ during exercise was lowered at $5,000 \mathrm{~m}(\mathrm{P}<0.001)$, with lesser reduction observed in the Tibetans compared to Han (interaction: $P=0.013)$. Regardless of the ethnicity, there were no effects of inhaled furosemide or iloprost on $\mathrm{SaO}_{2}$ at exhaustion, i.e. exhaustion was reached at similar $\mathrm{SaO}_{2}$.
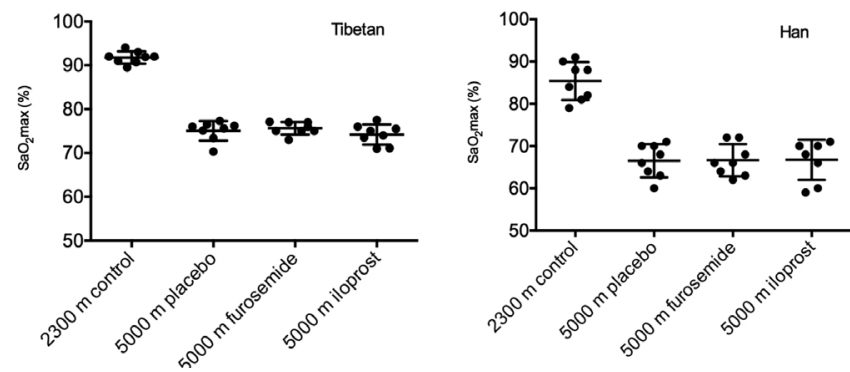

Figure 2: Saturation at maximum exercise effort. Dots indicate individuals. Bars and flankers indicate means \pm SD.

\section{Maximum heart rate}

No difference in maximum heart rate was observed between Tibetan and Han during exercise at 2,260 m ( $P=0.361)$. During exercise at $5,000 \mathrm{~m}$, for any given submaximal exercise intensity, HR was higher compared to at 2,260 m ( $P=0.035)$. The absolute increase in $\mathrm{HR}$ during exercise was greater in Tibetans (interaction: $\mathrm{P}=0.009$ ), due to the higher maximal exercise intensity achieved compared to Han. In Han, maximum heart rate was decreased by $13 \pm 6 \mathrm{bpm}$ during exercise at $5,000 \mathrm{~m}$ with placebo $(\mathrm{P}<0.001)$. Compared to placebo, neither iloprost nor furosemide influenced maximum heart rate in the Han. In
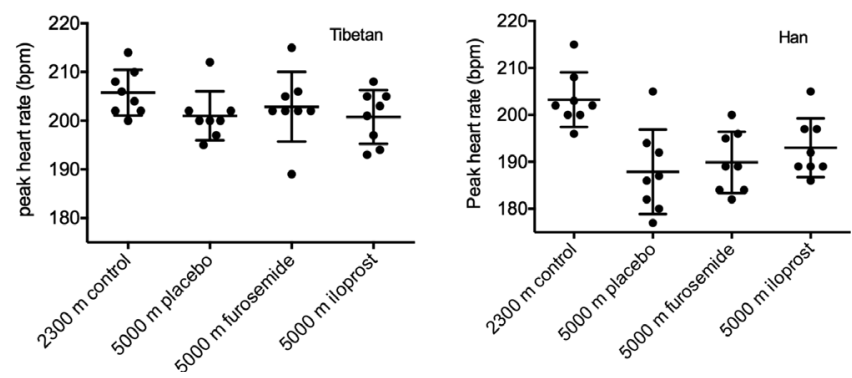

Figure 3: Heart rate at maximum exercise effort. Dots indicate individuals. Bars and flankers indicate means \pm SD.
Tibetans, exercise at 5,000 m lowered maximum heart rate by $5 \pm 3 \mathrm{bpm}(\mathrm{P}=0.027)$ with placebo. Meanwhile, no difference in maximum heart rate was observed with furosemide and iloprost compared to placebo in Tibetans during exercise at 5,000 m.

\section{Discussion}

This study examined the effects of inhalation of iloprost and furosemide on incremental inclined treadmill running performance at 5,000 $\mathrm{m}$ in Han and Tibetans. We report three unique findings: 1) Inhalation of iloprost improved running performance by $50 \mathrm{sec}(95 \% \mathrm{Cl}, 15$ to $86 \mathrm{sec})$ in Han Chinese at $5,000 \mathrm{~m}$, while it had no effect in the Tibetans $(95 \% \mathrm{Cl},-35$ to $36 \mathrm{sec}) ; 2$ ) Inhalation of furosemide had no significant effects in either Han or Tibetans; and 3) During maximal exercise at 5,000 $\mathrm{m}$, the Tibetans were able to reach very high maximum heart rates ( 200 bpm), not yet reported before at such altitude, while maintaining a significantly better arterial saturation as compared to the Han.

Iloprost

Prostacyclin is a potent pulmonary vasodilator synthesized in the endothelium. It targets the IP receptor in the smooth muscle cells of the pulmonary vasculature. IP recepter activation triggers conversion of ATP to cyclic-AMP, which increases protein-kinase-A activity, leading to downstream effects including vasodilation (Humbert \& Ghofrani, 2015). lloprost is a prostacyclin analogue. When inhaled its pulmonary vasodilatory potency is similar to that of prostacyclin, but the effects last longer (30 to $90 \mathrm{~min}, \mathrm{vs.} 15 \mathrm{~min}$ for prostacyclin (Olschewski et al., 2002; Waxman \& Zamanian, 2013)). In our iloprost-naïve participants we used the recommended initial dose of 10 microgram, which was inhaled over a period of about 10-15 min prior to the start of the resting measurements. The full testing sequence was completed within an hour, so that our results were obtained inside the therapeutic window of inhaled iloprost. We found that iloprost inhalation improved performance in Han at 5,000 m, while no effect was observed in the Tibetans (Table 3). Wensel et al.(2000) reported that iloprost inhalation decreased pulmonary vascular resistance and improved exercise time by $16 \%$ in primary pulmonary hypertension patients. Therefore, whilst speculative, we attribute the improvement in running performance we found in the Han to an attenuation of hypoxia-induced pulmonary hypertension during maximum exercise with iloprost. However, since we were unable to measure PAP during exercise, strong conclusions cannot be drawn. Our findings would seem to support recent observations of a relationship between borderline pulmonary hypertension and aerobic exercise performance in young otherwise healthy Chinese lowlanders in conditions of acute and chronic altitude exposure (Yang et al., 2014). Our data also corroborate reports of partial improvements (10-25\%) in maximal exercise 
capacity in hypoxia with other specific pulmonary vasodilating interventions (Ghofrani et al., 2004; Naeije \& Dedobbeleer, 2013). Since iloprost had no effect in the Tibetans, our results would then suggest that HPV is not a limiting factor for exercise performance in the Tibetan population. Nevertheless, our data provide only limited evidence supporting a role for HPV in limiting performance in Han at high altitude.

\section{Furosemide}

Others proposed that the decrease in maximum heart rate at altitude is due to increased parasympathetic activity (Bao et al., 2002; Boushel et al., 2001). Furosemide is a loop diuretic which inhaled can alleviate symptoms of dyspnea (Newton et al., 2008; Parshall et al., 2012), perhaps through pulmonary vagal receptor inhibition, decreasing vagal afferent traffic (Lee \& Pisarri, 2001; Newton et al., 2008). We therefore hypothesized that heart rate during maximal exercise in hypoxia would increase under inhalation of furosemide because of less parasympathetic activity. In the present study, maximum heart rate was not significantly different in the Han after furosemide inhalation compared to placebo ( $+2 \mathrm{bpm}[95 \% \mathrm{Cl},-2$ to +6$]$ ). Accordingly, this finding refutes our hypothesis of pulmonary receptor stimulation causing increased parasympathetic activity limiting maximum heart rate during hypoxic exercise. However, pulmonary receptors and their role in limiting maximum heart rate in severe hypoxia are still not yet well understood (Widdicombe, 2009). In rabbits basal rapid adapting pulmonary receptor (RAR) activity increases during prolonged exposure to hypoxia accompanied by pulmonary congestion (Bhagat et al., 2011). In humans, exposure to high altitude is accompanied by pulmonary congestion and subclinical interstitial pulmonary edema (Anholm et al., 1999; Cremona et al., 2002). It therefore remains possible that increased PAP (from altitude and exercise) and interstitial oedema would stimulate vagal pulmonary receptors, leading to increased parasympathetic activity, in turn leading to decreased peak heart rates, even though the absence of an effect of inhaled furosemide in our study would argue against this contention.

\section{Maximum heart rates in Tibetans}

Strikingly, on average our Tibetan participants reached peak heart rates above $200 \mathrm{bpm}$, independently of the altitude or the intervention, contrary to what was expected from the extant literature (Mourot, 2018). Our participants were young (20 \pm 2 $\mathrm{yr}$ ) and heart rates around $200 \mathrm{bpm}$ were therefore expected in normoxic conditions, but not necessarily at 2,260 m, and certainly not at 5,000 m. More important, the Tibetans reached similar peak heart rates in all conditions. This finding is contrary to the prevailing view of decreased peak heart rates above about 4,000 m (Bao et al., 2002; Boushel et al., 2001; Wagner, 2000). At lower altitudes peak heart rate remains similar to that observed at sea level, but beyond $4,000 \mathrm{~m}$ peak heart rate progressively decreases with increasing altitude, while chronic exposure to hypoxia decreases it even further, because of the increased $\mathrm{CaO}_{2}$ from the increased haemoglobin. For example, Danish climbers attempting Mt Everest, who prior to departure had mean peak heart rates of $186 \mathrm{bpm}$ in normoxia, and 170 bpm in acute hypoxia ( $10 \% \mathrm{O}_{2}$ in $\mathrm{N}_{2}$ ), after acclimatization at $5,400 \mathrm{~m}$ reached peak heart rates of only $155 \mathrm{bpm}$ (Lundby \& van Hall, 2001). In that study, in two climbers heart rate was monitored during ascent to $8,750 \mathrm{~m}$ (without supplementary $\mathrm{O}_{2}$ ), with peak rates of only 144 and $148 \mathrm{bpm}$, respectively.

The reasons for the decrease in peak heart rate in acute and chronic severe hypoxia are unknown (Mourot, 2018). In lowlanders, after 9 weeks at 5,260 m, vagal blockade with glycopyrrolate restored maximum heart rate to sea level values, but had no influence on cardiac output or performance, which remained reduced, while acutely normalizing $\mathrm{FiO}_{2}$ at peak exercise restored cardiac output and power output to sea level values (Boushel et al., 2001). Those authors concluded that enhanced parasympathetic neural activity accounts for the lowering of heart rate during exercise at altitude, but could not explain why blocking parasympathetic activity did not improve performance. Bao et al. (2002) investigated the effects of beta-blockade with propranolol and para-sympathetic blockade with glycopyrrolate and reported that increased parasympathetic neurotransmitter release and decreased betaadrenoreceptor activity account for the decreased peak heart rates, despite enhanced sympathetic activity. An acute increase in $\mathrm{FiO}_{2}$ rapidly counteracted the parasympathetic, but not the sympathetic hyperactivity that occurred at high altitude (Bao et al., 2002). Favret and Richalet hypothesized that the drop in maximum heart rate in severe hypoxia would prevent mismatching between myocardial $\mathrm{O}_{2}$ demand and supply (Favret \& Richalet, 2007). They reasoned that compensation of decreased $\mathrm{CaO}_{2}$ in severe hypoxia by increasing coronary blood flow would not be possible anymore above a certain altitude. Only by capping maximal heart rate, which would decrease myocardial $\mathrm{O}_{2}$ demand, would cardiac integrity be protected. Our results suggest that this would not be the case for Tibetans exercising maximally at $5,000 \mathrm{~m}$, but leaves the hypothesis to be tested in even more severe hypoxia such as found close to the summit of Mt Everest (8848 m).

\section{Limiting factors of exercise performance in hypoxia}

The impairment of aerobic power and exercise performance in severe hypoxia $\left(\mathrm{SaO}_{2}<80 \%\right)$ is still not well understood. Lack of oxygen is obviously the reason, but the underlying mechanisms that lead to an earlier disengagement from an exercise challenge in hypoxia compared to normoxia remain unknown (Fan \& Kayser, 2016). According to Verges et al. (2012) active locomotor muscle metabolic fatigue cannot be the main cause of the impaired whole body exercise performance in severe hypoxia. Upon reaching exhaustion in hypoxia, participants can continue cycling when surreptitiously switched to normoxia (Amann et al., 2006; Boushel et al., 2001; Kayser et al., 1994; Koglin \& Kayser, 2013), which also argues in favour of a 
supra-spinal limitation of exercise performance (Fan \& Kayser, 2016). Amann et al. (2007) reported that the degree of hypoxia influences the relative role of muscle fatigue in the cessation of dynamic exercise with large muscle groups. Those authors proposed a threshold of $\mathrm{SaO}_{2}$ for a 'switch' from a predominant effect of peripheral fatigue to one of a supra-spinal limitation. They found similar levels of muscle fatigue at task failure from constant load exercise to exhaustion in different conditions of inspiratory oxygen tension, when $\mathrm{SaO}_{2}$ averaged $94 \%, 82 \%$, or $76 \%\left(\mathrm{FiO}_{2} 0.21-0.12\right)$, but not at a $\mathrm{SaO}_{2}$ of $67 \%\left(\mathrm{FiO}_{2} 0.10\right)$ when apparently supra-spinal limitation led to early disengagement of the effort. When reaching exhaustion at 5,000 m our Han Chinese participants had on average saturations of about $67 \%$, similar to that of Amann's participants. This would suggest that limitation of exercise at 5,000 m in our Han participants may have been less from peripheral muscle fatigue as compared to 2,260 $\mathrm{m}$ and that supra-spinal effects would have played a predominant role. By contrast, our Tibetan participants had significantly higher saturations as compared to the Han participants, on average remaining higher than $74 \%$ at maximum exercise, i.e. at or just above the supposed 'switch' value between 76 and $67 \%$ as suggested by Amann et al. (2007). It therefore remains possible that the 'switch' from predominantly peripherally determined fatigue towards a supra-spinal mechanism could exist in the Tibetans too, but at higher altitudes, when their $\mathrm{SaO}_{2}$ could drop below $67 \%$. One other feature with regard to $\mathrm{SaO}_{2}$ made the Tibetans stand out. Apart from being higher, their saturations were all very similar; variance was lower as compared to that of the Han, as can be clearly seen in Figure 1. We do not have an explanation for the better saturations of the Tibetans as compared to the Han Chinese, nor for the reduced variance. An increased affinity for oxygen of haemoglobin could play a role. Simonson et al. (2014) reported lower haemoglobin P50 in Han Chinese and Tibetans at 4,200 $\mathrm{m}$ in comparison with low altitude data, but no difference between the two groups, excluding a role for P50.

\section{Tibetans and altitude}

It is beyond the scope of this study to comprehensively review what is known about the Tibetans' better adaptation to altitude as compared to other ethnic groups. But with regard to exercise performance there is sufficient research suggesting that Tibetans do indeed fare better [see e.g. (Wu \& Kayser, 2006)]. Tibetans do not have very high aerobic capacity, but are able to reach a higher fraction of their low-altitude aerobic capacity in hypoxia as compared to lowlanders (Marconi et al., 2004; Niu et al., 1995). Since this characteristic is also present in Tibetans born at low altitude this suggests a trait for better altitude adaptation (Marconi et al., 2004). Recent work suggests that hypoxic exposure over many generations indeed led to the selection of specific alleles in Himalayan (Simonson, McClain, Jorde, \& Prchal, 2012), but also Andean (Brutsaert et al., 2004), and East-African highlanders (Scheinfeldt et al., 2012).

\section{Limitations}

Several important methodological limitations should be considered when interpreting our findings. First, iloprost was expected to alleviate HPV and thus lower PAP, but we were not able to measure PAP. Our results, even though compatible with a role for HPV in limiting performance in the Han, should therefore be completed with new data including measurements of PAP during exercise, e.g. with echo-doppler. Second, since we did not measure stroke volume or cardiac output, we could only infer cardiovascular changes from observing changes in heart rates. However, since there was a clear difference between the Han and the Tibetans with regard to heart rate it seems likely that they did differ for cardiac output, but this remains to be tested, e.g. with acetylene rebreathing, echo-doppler or transthoracic impedancemetry. Third, we were unable to recruit participants of similar stature, resulting in slightly smaller and lighter Tibetan participants compared to their Han Chinese counterparts. Our results should therefore be completed with measurements in more participants and with similar build. Fourth, because of calibration problems of our gas exchange apparatus upon decompression to $5,000 \mathrm{~m}$ we could not obtain reliable gas exchange data. Fifth, we cannot present any rates of perceived exertion for leg and breathing effort since the participants did not understand the instructions. Sixth, we cannot ascertain maximality of the running effort with usual criteria such as high RPE, a plateau in $\mathrm{VO}_{2^{\prime}}$ and an RER $>1.1$. And finally, since we used the actual living altitude of $2,260 \mathrm{~m}$ of our participants as our control condition, and not (acute) sea level conditions, we cannot exclude some effect of partial acclimatization to high altitude.

\section{Conclusions}

We report conserved maximum heart rate and less desaturation during maximum exercise in acute severe hypoxia $(5,000$ m) in Tibetans compared to Han, allowing the Tibetans to outperform the Han. Since inhalation of iloprost blunted the exercise impairment in Han during maximal exercise in severe hypoxia but had no effect in Tibetans, HPV possibly plays a role in the greater impact of hypoxia on maximum exercise capacity in Han as compared to Tibetans.

\section{Acknowledgements}

We thank the participants for their participation, the technical support personnel of the hypobaric chamber at the National Key Laboratory of High Altitude Medicine in Xining for their expert help, and Aeroneb, Galway, Ireland, for donation of nebulizers. 


\section{Funding}

We acknowledge the support of the Sino Swiss Science and Technology Cooperation Program and a Chinese research grant 973-2012CB18202.

\section{Competing Interests}

The authors have declared that no competing interests exist.

\section{Data Availability Statement}

The datasets used can be made available from the corresponding author on reasonable request.

\section{References}

Amann, M., \& Calbet, J. A. L. (2008). Convective oxygen transport and fatigue. Journal of Applied Physiology (Bethesda, Md.: 1985), 104(3), 861-870. doi: 10.1152/ japplphysiol.01008.2007

Amann, M., \& Kayser, B. (2009). Nervous system function during exercise in hypoxia. High Altitude Medicine \& Biology, 10(2), 149-164. doi: 10.1089/ham.2008.1105

Amann, M., Eldridge, M. W., Lovering, A. T., Stickland, M. K., Pegelow, D. F., \& Dempsey, J. A. (2006). Arterial oxygenation influences central motor output and exercise performance via effects on peripheral locomotor muscle fatigue in humans. The Journal of Physiology, 575(Pt 3), 937-952. doi: 10.1113/jphysiol.2006.113936

Amann, M., Romer, L. M., Subudhi, A. W., Pegelow, D. F., \& Dempsey, J. A. (2007). Severity of arterial hypoxaemia affects the relative contributions of peripheral muscle fatigue to exercise performance in healthy humans. The Journal of Physiology, 581(Pt 1), 389-403. doi: 10.1113/ jphysiol.2007.129700

Anholm, J. D., \& Foster, G. P. (2011). Con: Hypoxic Pulmonary Vasoconstriction Is not a Limiting Factor of Exercise at High Altitude. High Altitude Medicine \& Biology, 12(4), 313-317. doi: 10.1089/ham.2011.1059

Anholm, J. D., Milne, E. N., Stark, P., Bourne, J. C., \& Friedman, P. (1999). Radiographic evidence of interstitial pulmonary edema after exercise at altitude. Journal of Applied Physiology, 86(2), 503-509.

Bao, X., Kennedy, B. P., Hopkins, S. R., Bogaard, H. J., Wagner, P. D., \& Ziegler, M. G. (2002). Human autonomic activity and its response to acute oxygen supplement after high altitude acclimatization. Autonomic Neuroscience, 102(1), 54-59. doi: 10.1016/S1566-0702(02)00174-1

Bhagat, R., Yasir, A., Vashisht, A., Kulshreshtha, R., Singh, S. B., \& Ravi, K. (2011). High altitude simulation, substance $P$ and airway rapidly adapting receptor activity in rabbits.
Respiratory Physiology \& Neurobiology, 178(2), 329-336. doi: 10.1016/j.resp.2011.07.005

Boushel, R., Calbet, J. A. L., Radegran, G., Sondergaard, H., Wagner, P. D., \& Saltin, B. (2001). Parasympathetic neural activity accounts for the lowering of exercise heart rate at high altitude. Circulation, 104(15), 1785-1791. doi: 10.1161/ hc4001.097040

Brutsaert, T. D., Parra, E., Shriver, M., Gamboa, A., Palacios, J.-A., Rivera, M., et al. (2004). Effects of birthplace and individual genetic admixture on lung volume and exercise phenotypes of Peruvian Quechua. Am J Phys Anthropol, 123(4), 390-398. doi: 10.1002/ajpa.10319

Chapman, R. F., Emery, M., \& Stager, J. M. (1999). Degree of arterial desaturation in normoxia influences $\mathrm{O}_{2 \max }$ decline in mild hypoxia. Medicine and Science in Sports and Exercise, 31(5), 658-663. doi: 10.1097/00005768-199905000-00006

Chapman, R. F., Stager, J. M., Tanner, D. A., Stray-gundersen, J., \& Levine, B. D. (2011). Impairment of 3000-m Run Time at Altitude is influenced by Arterial Oxyhemoglobin Saturation. Medicine and Science in Sports and Exercise, 43(9), 1649-1656. doi: 10.1249/MSS.0b013e318211bf45

Cremona, G., Asnaghi, R., Baderna, P., Brunetto, A., Brutsaert, T., Cavallaro, C., et al. (2002). Pulmonary extravascular fluid accumulation in recreational climbers: a prospective study. The Lancet, 359(9303), 303-309. doi: 10.1016/S01406736(02)07496-2

Dempsey, J. A., \& Wagner, P. D. (1999). Exercise-induced arterial hypoxemia. Journal of Applied Physiology (Bethesda, Md.: 1985), 87(6), 1997-2006.

Fan, J.-L., \& Kayser, B. (2016). Fatigue and exhaustion in hypoxia: The role of cerebral oxygenation. High Altitude Medicine \& Biology, 17(2), 72-84. doi: 10.1089/ham.2016.0034

Favret, F., \& Richalet, J.-P. (2007). Exercise and hypoxia: The role of the autonomic nervous system. Respiratory Physiology \& Neurobiology, 158(2-3), 280-286. doi: 10.1016/j. resp.2007.04.001

Ferretti, G., Moia, C., Thomet, J. M., \& Kayser, B. (1997). The decrease of maximal oxygen consumption during hypoxia in man: a mirror image of the oxygen equilibrium curve. The Journal of Physiology, 498 (Pt 1), 231-237.

Ghofrani, H. A., Reichenberger, F., Kohstall, M. G., Mrosek, E. H., Seeger, T., Olschewski, H., et al. (2004). Sildenafil increased exercise capacity during hypoxia at low altitudes and at Mount Everest base camp: a randomized, double-blind, placebo-controlled crossover trial. Annals of Internal Medicine, 141(3), 169-177.

Groves, B. M., Sutton, J., Droma, T., McCullough, R. G., McCullough, R. E., Zhuang, J., et al. (1993). Minimal hypoxic pulmonary hypertension in normal Tibetans at 3,658 $\mathrm{m}$. Journal of Applied Physiology, 74(1), 312-318.

Humbert, M., \& Ghofrani, H.-A. (2015). The molecular targets of approved treatments for pulmonary arterial hypertension. Thorax, 71(1), 73-83. doi: 10.1136/thoraxjnl-2015-207170

Jensen, D., Amjadi, K., Harris-McAllister, V., Webb, K. A., \& O'Donnell, D. E. (2008). Mechanisms of dyspnoea relief 
and improved exercise endurance after furosemide inhalation in COPD. Thorax, 63(7), 606-613. doi : 10.1136/ thx.2007.085993

Kayser, B., Narici, M., Binzoni, T., Grassi, B., \& Cerretelli, P. (1994). Fatigue and exhaustion in chronic hypobaric hypoxia: influence of exercising muscle mass. Journal of Applied Physiology (Bethesda, Md.: 1985), 76(2), 634-640.

Koglin, L., \& Kayser, B. (2013). Control and sensation of breathing during cycling exercise in hypoxia under naloxone: a randomised controlled crossover trial. Extreme Physiology \& Medicine, 2(1), 1. doi: 10.1186/2046-7648-2-1

Lee, L.-Y., \& Pisarri, T. E. (2001). Afferent properties and reflex functions of bronchopulmonary C-fibers. Neuroscience \& Biobehavioral Reviews, 125(1-2), 47-65. doi: 10.1016/S00345687(00)00204-8

Lundby, C., \& van Hall, G. (2001). Peak heart rates at extreme altitudes. High Altitude Medicine \& Biology, 2(1), 41-45. doi: 10.1089/152702901750067909

Marconi, C., Marzorati, M., Grassi, B., Basnyat, B., Colombini, A., Kayser, B., \& Cerretelli, P. (2004). Second generation Tibetan lowlanders acclimatize to high altitude more quickly than Caucasians. The Journal of Physiology, 556(Pt 2), 661-671. doi: 10.1113/jphysiol.2003.059188

Mourot, L. (2018). Limitation of maximal heart rate in hypoxia: mechanisms and clinical importance. Frontiers in Physiology, 9, 972. doi: 10.3389/fphys.2018.00972

Naeije, R. (2011). Pro: Hypoxic pulmonary vasoconstriction is a limiting factor of exercise at high altitude. High Altitude Medicine \& Biology, 12(4), 309-312. doi: 10.1089/ ham.2011.1060

Naeije, R., \& Chesler, N. (2012). Pulmonary circulation at exercise. Comprehensive Physiology, 2(1), 711-741. doi: 10.1002/cphy. c100091

Naeije, R., \& Dedobbeleer, C. (2013). Pulmonary hypertension and the right ventricle in hypoxia. Experimental Physiology, 98(8), 1247-1256. doi: 10.1113/expphysiol.2012.069112

Naeije, R., Huez, S., Lamotte, M., Retailleau, K., Neupane, S., Abramowicz, D., \& Faoro, V. (2010). Pulmonary artery pressure limits exercise capacity at high altitude. European Respiratory Journal, 36(5), 1049-1055. doi: 10.1183/09031936.00024410

Newton, P. J., Davidson, P. M., Macdonald, P., Ollerton, R., \& Krum, H. (2008). Nebulized furosemide for the management of dyspnea: Does the evidencesupportits use? Journal of Pain and Symptom Management, 36(4), 424-441. doi: 10.1016/j. jpainsymman.2007.10.017

Nielsen, H. B. (2003). Arterial desaturation during exercise in man: implication for $\mathrm{O}_{2}$ uptake and work capacity. Scandinavian Journal of Medicine and Science in Sports, 13(6), 339-358. doi: 10.1046/j.1600-0838.2003.00325.x

Niu, W., Wu, Y., Li, B., Chen, N., \& Song, S. (1995). Effects of long-term acclimatization in lowlanders migrating to high altitude: comparison with high altitude residents. European Journal of Applied Physiological Occupational Physiology, $71(6), 543-548$.
Olschewski, H., Simonneau, G., Galiè, N., Higenbottam, T., Naeije, R., Rubin, L. J., et al. (2002). Inhaled iloprost for severe pulmonary hypertension. The New England Journal of Medicine, 347(5), 322-329. doi: 10.1056/NEJMoa020204

Parshall, M. B., Schwartzstein, R. M., Adams, L., Banzett, R. B., Manning, H. L., Bourbeau, J., et al. (2012). An official American Thoracic Society Statement: Update on the mechanisms, assessment, and management of dyspnea. American Journal of Respiratory and Critical Care Medicine, 185(4), 435-452. doi: 10.1164/rccm.201111-2042ST

Paton, J. F. (1998). Pattern of cardiorespiratory afferent convergence to solitary tract neurons driven by pulmonary vagal C-fiber stimulation in the mouse. Journal of Neurophysiology, 79(5), 2365-2373.

Scheinfeldt, L. B., Soi, S., Thompson, S., Ranciaro, A., Woldemeskel, D., Beggs, W., et al. (2012). Genetic adaptation to high altitude in the Ethiopian highlands. Genome Biology, 13(1), R1. doi: 10.1126/science.1117196

Simonson, T. S., McClain, D. A., Jorde, L. B., \& Prchal, J. T. (2012). Genetic determinants of Tibetan high-altitude adaptation. Human Genetics, 131(4), 527-533. doi: 10.1007/s00439-0111109-3

Simonson, T. S., Wei, G., Wagner, H. E., Wuren, T., Bui, A., Fine, J. M., et al. (2014). Increased blood-oxygen binding affinity in Tibetan and Han Chinese residents at $4200 \mathrm{~m}$. Experimental Physiology, 99(12), 1624-1635. doi: 10.1113/ expphysiol.2014.080820

Sun, S. F., Droma, T. S., Zhang, J. G., Tao, J. X., Huang, S. Y., McCullough, R. G., et al. (1990). Greater maximal $\mathrm{O}_{2}$ uptakes and vital capacities in Tibetan than Han residents of Lhasa. Neuroscience \& Biobehavioral Reviews, 79(2), 151-162. doi: 10.1016/0034-5687(90)90015-Q

Verges, S., Rupp, T., Jubeau, M., Wuyam, B., Esteve, F., Levy, P., et al. (2012). Cerebral perturbations during exercise in hypoxia. American Journal of Physiology, 302(8), R903-R916. doi: 10.1152/ajpregu.00555.2011

Wagner, P. D. (2000). Reduced maximal cardiac output at altitude--mechanisms and significance. Respiration Physiology, 120(1), 1-11.

Waxman, A. B., \& Zamanian, R. T. (2013). Pulmonary arterial hypertension: new insights into the optimal role of current and emerging prostacyclin therapies. American Journal of Cardiology, 111(5 Suppl), 1A-16A- quiz 17A-19A. doi: 10.1016/j.amjcard.2012.12.002

Wensel, R., Opitz, C. F., Ewert, R., Bruch, L., \& Kleber, F. X. (2000). Effects of iloprost inhalation on exercise capacity and ventilatory efficiency in patients with primary pulmonary hypertension. Circulation, 101(20), 2388-2392.

Widdicombe, J. (2009). Lung afferent activity: Implications for respiratory sensation. Respiratory Physiology \& Neurobiology, 167(1), 2-8. doi: 10.1016/j.resp.2008.09.012

Wu, T., \& Kayser, B. (2006). High altitude adaptation in Tibetans. High Altitude Medicine \& Biology, 7(3), 193-208. doi: 10.1089/ ham.2006.7.193 
Yang, T., Li, X., Qin, J., Li, S., Yu, J., Zhang, J., et al. (2014). High altitude-induced borderline pulmonary hypertension impaired cardiorespiratory fitness in healthy young men. International Journal of Cardiology, 181C, 382-388. doi: 10.1016/j.ijcard.2014.12.044

Zhou, Z.-N., Zhuang, J.-G., Wu, X.-F., Zhang, Y., \& Cherdrungsi, P. (2008). Tibetans retained innate ability resistance to acute hypoxia after long period of residing at sea level. The Journal of Physiological Sciences: JPS, 58(3), 167-172. doi: 10.2170/physiolsci.RP009207

Zhuang, J., Sutton, J., Droma, T., McCullough, R. E., McCullough, R. G., Groves, B. M., et al. (1993). Autonomic regulation of heart rate response to exercise in Tibetan and Han residents of Lhasa (3,658 m). Journal of Applied Physiology (Bethesda, Md. : 1985), 75(5), 1968-1973. 
